\title{
Intervención de las Funciones Ejecutivas en estudiantes de Educación Superior con Trastorno de Déficit de la Atención
}

\author{
Katia Sandoval-Rodríguez. Pontificia Universidad Católica de Valparaíso \\ Eva María Olmedo-Moreno. Universidad de Granada \\ Recepción: 30 de mayo de 2017 Aceptado: 15 de diciembre de 2017 \\ Correspondencia: Katia Sandoval-Rodríguez | Correo-e: katia.sandoval@pucv.cl
}

\section{iD 0000-0003-2871-9351}

Citar: Sandolvan-Rodriguez, K. y Olmedo-Moreno, EM. (2017). Intervención de las Funciones Ejecutivas en estudiantes de Educación con Trastorno de Déficit de la Atención. ReiDoCrea, 6, 320-342.

Resumen: Los desafíos que conlleva el ingreso a la Educación Superior para estudiantes que presentan Trastorno de Déficit de la Atención requiere un desarrollo adecuado de sus Funciones Ejecutivas. Esta investigación buscaba identificar posibles cambios en estudiantes de educación superior con diagnóstico de Trastorno de Déficit de la Atención TDAH y bajo rendimiento académico, tras realizar un proceso de intervención psicopedagógica basado en una propuesta de desarrollo de Funciones Ejecutivas denominado Tres Momentos para Aprender. Por medio de un estudio de casos múltiple se investiga a seis estudiantes universitarios entre 22 y 30 años, de diferentes universidades de Valparaíso, Chile. Los resultados indican que los estudiantes presentaban dificultades de funcionamiento a nivel académico, social y familiar, bajo autoconcepto académico y carecían de estrategias de comprensión y compensación del TDAH. Tras la intervención evidencian cambios positivos en varios ámbitos, conciencia de los mismos y un rendimiento académico adecuado.

Palabras Clave: Educación Superior | Funciones Ejecutivas

Intervention of Executive Functions in Higher Education Students with Attention Deficit Disorder

Abstract: The challenges of entering higher education for students with Attention Deficit Disorder require an adequate development of their Executive Functions. This research study aimed to identify possible changes in students of higher education with a diagnosis of Attention Deficit Hyperactivity Disorder (ADHD) and low academic performance, after conducting a psychopedagogical intervention process based on a model of Executive Function development called Three Moments to Learn. Through a multiple case study, six university students between the ages of 22 and 30, from different universities in Valparaíso, Chile were investigated. Results indicate that the students presented difficulties functioning at academic, social and family level, had low academic self-concept and lacked strategies for understanding and compensation of ADHD. After the intervention they show positive changes in several areas, awareness of them and an adequate academic performance.

Keywords: Higher Education | Executive Functions

\section{Introducción}

La educación superior ha implicado por años un desafío para quienes ingresan buscando obtener un grado académico y/o títulos específicos, pues deben poner en ejercicio habilidades personales adquiridas y desarrolladas en los años anteriores de formación, habilidades que deben estar dirigidas hacia la determinación de metas de aprendizaje, al logro de objetivos específicos, estrategias de monitoreo, seguimiento de las tareas planificadas y valoración de los resultados asociados a estas, lo que implica desde una concepción constructivista del aprendizaje, que este estudiante sea autónomo (Garello \& Rinaudo, 2013, Rosário et al., 2012). En donde hoy la propuesta de las universidades se orienta hacia una concepción del aprendizaje constructivista basada en el aprendizaje significativo, donde se busca un estudiante es autónomo, auto-regulado, que conoce sus propios procesos cognitivos y tiene en sus manos el control del aprendizaje (Olmedo Moreno, 2013) 
En este contexto, el uso de estrategias efectivas de estudio y un actuar autorregulado constituyen para un estudiante de educación superior variables importantes para el éxito en el desempeño académico y la vida diaria (Alvarado, Vega, Cepeda, \& Del Bosque, 2014; Arias, Rodríguez, Cabanach, Pérez, \& Rosário, 2009). Asimismo se requiere que los estudiantes posean adecuados niveles de funcionamiento ejecutivo, principalmente a nivel de planificación, automonitoreo, control emocional, inhibición, flexibilidad, memoria de trabajo, entre otros (Garello \& Rinaudo, 2013)

En este escenario, existe un grupo de estudiantes de educación superior que superan sin contrariedades el proceso de selección universitaria e ingresan a esta en forma expedita, pero al poco tiempo de ingresar presentan importantes dificultades de rendimiento académico, lo que para algunos resulta ser la primera vez a la que se ven enfrentados a este tipo de fracaso. Esta situación puede ser explicada por una variedad de factores, como son: dificultades económicas, transición difícil a este nivel educativo, desconcierto ante las exigencias particulares de la vida universitaria, escasa utilización de estrategias de estudio o poseer una percepción de un rendimiento no satisfactorio al verse enfrentados a prácticas educativas ajenas a sus necesidades habituales (Silva Laya, 2011) y de manera muy relevante el poseer un diagnóstico de Trastorno de Déficit de la Atención TDAH desde la infancia.

\section{Trastorno de Déficit de Atención TDAH en aprendices adultos}

El Trastorno de Déficit de la Atención TDAH es una de las posibles causales del bajo rendimiento académico en universitarios (Barragán Bech, Lewis Harb \& Palacio Sañudo, 2007; Montiel, Ortiz, Jaimes \& González, 2012), pues se caracteriza por ser un trastorno severo del neurodesarrollo que conlleva dificultades en el control ejecutivo del comportamiento afectando las tareas académicas con posibles reprobaciones y deserciones, así como dificultades en las relaciones familiares y sociales (American Psychiatric Association, 2013; Barkley 2015; Cardo \& Servera, 2008; Lavigne \& Romero, 2010) siendo por tanto una de las mayores causas de derivación a los sistemas de salud mental.

Hoy en día, la evidencia internacional indica que el TDAH es una condición que se mantiene hasta la adultez, donde niños con este diagnóstico siguen presentando las mismas características (Barkley 2015; Rodríguez-Jiménez et al., 2006,) en la adolescencia y en la vida adulta en una prevalencia entre un 1 y $5 \%$ de la población (Biederman et al., 2012, Ramos-Quiroga et al., 2006). En la población adulta, las personas con diagnóstico de TDAH son entre un 3-5\% a nivel mundial, sin embargo en estudiantes universitarios las cifras fluctúan entre un $0,5 \%$ hasta un $7 \%$ (Montiel et al, 2012).

Se han llevado a cabo más de 3.000 estudios vinculados al TDAH (Barkley, 2009) y se ha comprobado que este trastorno tiene características crónicas (Miranda \& Soriano, 2000), que es propio de la infancia y la adolescencia, pero los síntomas y el impacto funcional del mismo no siempre desaparecen en la adultez y pueden persistir en el $50 \%$ de los casos (Aragonès et al., 2010; Faraone, 2005; Ramos-Quiroga et al., 2013; Roizblatt, Bustamante, \& Bacigalupo, 2003). Con una prevalencia en la población adulta entre 4 y $5 \%$ (Adler, Solanto, Escobar, Lipsius, \& Upadhyaya, 2016; RamosQuiroga et al., 2013; Roizblatt et al., 2003) situándose como uno de los trastornos psiquiátricos más frecuentes, por encima de la esquizofrenia o el trastorno bipolar. En Chile, Roizblatt et al., (2003) estiman que el TDAH puede persistir en la edad adulta desde en una prevalencia estimada del 3 al $6 \%$ en la población general. Asimismo identifican características clínicas del TDAH en adultos: hiperactividad motora, 
impulsividad, déficit de atención, desorganización, hiperactividad emocional, temperamento explosivo y labilidad emocional.

Ahora bien, aunque existen antecedentes de niños con diagnóstico de TDAH que pueden ser capaces de afrontar de forma aceptable los aprendizajes, las relaciones sociales y la aceptación personal (Cardo \& Servera, 2008), se plantea que los adultos con un TDAH diagnosticado en la infancia muestran diferencias significativas en el rendimiento académico respecto a estudiantes sin el trastorno, logrando una menor formación académica en comparación con los grupos control, aun con niveles similares a nivel intelectual (Ramos-Quiroga et al., 2006), al mismo tiempo pueden presentar posibles dificultades interpersonales, académicas y laborales que afectan su vida, su rendimiento y específicamente la formación de su autoestima y autoeficacia (Newark \& Stieglitz, 2010). Esta condición deja de manifiesto la disfunción ejecutiva que conlleva el presentar un TDAH, sobre todo frente a los altos niveles de exigencia a los que se ven enfrentados, requiriendo algunos de ellos por primera vez una atención especializada para dar respuestas a estos nuevos requerimientos.

Barkley (2015) por su parte, ha propuesto el comprender y explicar el TDAH como modelo híbrido de autorregulación de las funciones ejecutivas con un fuerte énfasis en la inhibición y la memoria de trabajo. En este entendido se afirma que una deficiente capacidad del control inhibitorio genera alteraciones en el funcionamiento ejecutivo global, evidenciándose en alteraciones de la capacidad inhibitoria de respuestas impulsivas, modulación de niveles de alerta de acuerdo a las demandas del medio, y una fuerte inclinación a la búsqueda de gratificación inmediata (Ramos Galarza \& Pérez Salas, 2015). Condición similar en los adultos con TDAH, quienes también experimentan disfunción en las funciones ejecutivas lo que los caracteriza por obtener menores logros académicos, profesionales y encontrarse en ocasiones en una posición económica menor en comparación a otros adultos sin TDAH (Biederman et al., 2012)

En la actualidad se ha iniciado una comprensión y explicación del TDAH desde enfoques múltiples, en donde los actuales modelos consideran a la desatención, baja concentración y disfunción ejecutiva, como elementos motivacionales y emocionales (Marx, Höpcke, Berger, Wandschneider \& Herpertz, 2013) como características del trastorno. En este sentido, los modelos de doble proceso de déficit de atenciónhiperactividad (TDAH) en adultos sugieren que tanto las funciones ejecutivas como las instrumentales están relacionadas y que las dificultades de las FE pueden estar asociadas específicamente a síntomas de falta de atención, desorganización, pero no hiperactividad-impulsividad. Situación en que la falta de atención se asocia más con una velocidad lenta de respuesta y la hiperactividad-impulsividad en cambio con una velocidad más rápida (Nigg et al., 2005)

Los requerimientos de tiempo de estudio, de organización, de estructura y de iniciativa que demandan el cursar la educación superior, implican para un estudiante el poseer esquemas cognitivos, emocionales, conductuales y de funcionamiento, que le permitan desempeñarse en forma efectiva en esta etapa de aprendizaje (Garello \& Rinaudo, 2013). Sumado a ello, el entorno universitario es uno en que los estudiantes experimentan una abrupta disminución del apoyo que recibían de sus padres, así como un aumento en las tentaciones y distracciones (La Count, Hartung, Shelton, \& Stevens, 2015), lo que exige necesariamente una mayor autorregulación y gestión de sus funciones ejecutivas, situación que evidentemente está alterada en aquellos que presentan TDAH. 
En este contexto, el bajo rendimiento académico de un estudiante universitario que posee un TDAH y que no ha recibido intervención o bien desconoce su condición, lo que podría traer consigo alteraciones en su autoestima, abandono de los estudios y/o altas tasas de reprobación (Montiel-Navas, Ortiz, Jaimes, \& González-Ávila, 2012). Como también evidenciar dificultades en su empleabilidad futura, manejo del dinero, accidentes de tránsito, riesgos vitales, disfunciones en su desarrollo sexual y comorbilidades. Lo que en estudios longitudinales de personas con TDAH en la infancia, muestran diferencias significativas en el rendimiento académico en la edad adulta a diferencia de aquellos que no presentan TDAH

\section{Funciones Ejecutivas en el aprendiz adulto}

En la actualidad existe un número importante de investigaciones dedicadas a determinar el funcionamiento del cerebro humano y un número importante de ellas focalizadas en el estudio de las Funciones Ejecutivas FE. El término "funciones ejecutivas" propiamente tal, es atribuido por algunos autores a Lezak (1982), quien postula que las FE comprenden aquellas capacidades mentales necesarias para la formulación de objetivos, la planificación, la realización de planes para alcanzar los objetivos y la posibilidad de llevar a cabo estas actividades de manera eficaz.

Pribram en la década de los años 70 fue uno de los primeros en utilizar el término ejecutivo cuando se hacía referencia al funcionamiento de la corteza prefrontal. Desde entonces, al menos 30 o más construcciones se han incluido bajo el término genérico de FE, por lo que el concepto en sí aún es difícil de definir operacionalmente (Goldstein, Naglieri, Princiotta \& Otero, 2014). A la fecha se han identificado más de 33 definiciones diferentes de FE (Miranda, Presentación, Siegenthaler, \& Jara, 2013), entendidas como un amplio abanico de operaciones cognitivas (Pineda, 2000; Soprano, 2003) y autodirigidas (Servera-Barceló, 2005), así como requisitos importantes para resolver problemas eficientemente.

Se plantea que las funciones ejecutivas son procesos mentales superiores que dirigen el pensamiento, la acción y las emociones. Se las vincula a acciones de organización, anticipación, planificación, inhibición, memoria de trabajo, flexibilidad, autorregulación y control de la conducta, establecimiento de metas y diseño de planes. Goldstein, Naglieri, Princiotta, y Otero las definen de la siguiente manera:

La función ejecutiva (FE) ha llegado a ser un término general que se utiliza para una diversidad de procesos cognitivos, incluyendo la planificación, la memoria de trabajo, atención, inhibición, automonitoreo, autorregulación y la iniciativa, todas llevadas a cabo por las áreas prefrontales de los lóbulos frontales (2014. p.3).

Frente al gran número de investigaciones en las cuales se vinculan las FE con las alteraciones del neurodesarrollo y por ende con el TDAH, llama la atención la escasa información científica en relación a este funcionamiento en adultos, puesto que los hallazgos más comunes en adultos son anormalidades en la respuesta motora y en la interferencia en la inhibición, memoria de trabajo, atención sostenida, selectiva y flexibilidad. Los estudios desde sus orígenes en este campo han estado dirigidos hacia el daño del lóbulo frontal sufrido por adultos debido a diversas patologías o traumatismo y en la actualidad los estudios fisiológicos de las FE por medio de técnicas de neuroimagen se han incrementado sustancialmente entregando evidencias que las ubican no solo en el área prefrontal, sino también que en las regiones frontal y posterior de la corteza cerebral, así como regiones subcorticales (Chung, Weyandt, \& Swentosky, 2014). 
Modelos explicativos desarrollados a mediados de los años 70 como el del control cognitivo de Posner y Snyder y el de procesos controlados de Schiffrin y Schneider en la década de los años 80; el modelo de ejecutivo central de Baddeley a fines de los años 90 en sus estudios sobre la memoria de trabajo; el de sistema atencional supervisor realizado por Shallice en los años 2000, pasando por un modelo integrativo de Miller y Cohen's, hasta llegar al modelo de fenotipo extendido de Barkley en el 2011, resumen las funciones ejecutivas dándole una funcionalidad al concepto de autorregulación el cual estaría compuesto por la memoria de trabajo, el control emocional, la resolución de problemas, el análisis y la síntesis de objetivos, entre otros. Incluyendo además la planificación, auto-monitoreo, control de interferencia y la auto-motivación (Barkley, 2011).

Desde la propuesta de la Behavior Rating Inventory of Executive Function BRIEF (Gioia, Isquith, Guy \& Kenworthy, 2000) con su cuestionario de evaluación de las FE para padres y profesores en su primera versión y con autorreporte en la versión de BRIEF2 (2015), se enfatiza que las FE son una colección de procesos responsables de guiar, dirigir y gestionar el funcionamiento cognitivo, emocional y de comportamiento, particularmente durante la resolución de nuevos problemas, determinando nueve FE como son la inhibición, automonitoreo, cambio, control emocional, iniciativa, memoria de trabajo, planificación, orden de materiales y control de la tarea.

Específicamente en los adultos con TDAH, se han propuesto sistemas de evaluación de las FE a través de pruebas psicométricas, neuropsicológicas, escalas e inventarios que buscan conocer el nivel de desempeño del control ejecutivo, fluidez verbal, memoria de trabajo, entre otros (Goldstein \& Naglieri, 2014; Murray \& Ramage, 2000). Sin embargo, esto no ha constituido un tarea fácil por ser las FE un constructo multidimensional que aún no posee límites tan específicos, surgiendo por ende una serie de propuestas de evaluación e interpretaciones de los resultados (Soprano, 2003).

Existen hallazgos que dan cuenta que las FE más estudiadas y con mayores dificultades en los adultos con TDAH son las referidas a la inhibición, la flexibilidad cognitiva, la capacidad de planificación, la fluidez verbal y memoria de trabajo, similares a las encontradas en los niños (Rodríguez-Jiménez et al., 2006). Los adultos con este trastorno se caracterizan además por importantes dificultades en el planeamiento y organización, el manejo del tiempo, uso de la memoria y dificultades para completar las tareas que llevan a cabo (Adler et al., 2016). De igual modo, se han propuesto tres perspectivas para evaluar las FE en adultos, la primera de tipo clínica cualitativa a través de la observación de los sujetos en cuanto a sus conductas y comportamientos, la segunda desde la clínica investigativa o cuantitativa la cual utiliza pruebas estandarizadas para una aproximación más clínica y objetiva, y la experimental utilizada para el estudio de grupos con variables manipuladas de manera estricta (Pineda, David, 2000). Es habitual el uso de pruebas neuropsicológicas desde el punto de vista clínico investigativo pues permiten constatar los niveles de atención (focalizada, dividida, sostenida y selectiva), el control de los impulsos, la flexibilidad cognitiva, planeamiento, entre otros (Naglieri \& Otero, 2014).

Por otra parte, estudios actuales se han enfocado en determinar si el uso de psicoestimulantes (metilfenidato, atomoxetina) en el tratamiento del TDAH, evidencia mejoras en la disfunción ejecutiva que acompaña en ocasiones a este trastorno, con hallazgos similares en la efectividad clínica de los medicamentes en la sintomatología del TDAH, pero con algunas discrepancias en cuanto al tiempo de uso, al fármaco en particular, a las estrategias de disminución o retiro del mismo y en cuanto tiempo de 
iniciada la terapia las FE han evidenciado cambios en los participantes de los estudios (Adler et al., 2016; Biederman et al., 2012).

\section{Intervención Psicopedagógica de adultos con TDAH}

A partir de lo anteriormente expuesto, surge la necesidad de implementar procesos de intervención oportunos a nivel cognitivo y de FE, a estudiantes de educación superior con diagnóstico de TDAH que presenten bajo rendimiento académico, ya sea con diagnóstico desde la infancia o más tardíamente, pues las evidencias demuestran que se logran cambios fundamentales en sus resultados académicos y un aumento en su autoconcepto (Abad-Mas et al., 2011). Lo anterior se encuentra avalado por los estudios de Shaw et al. (2012) quienes concluyen a partir de una revisión sistemática de investigaciones de tratamientos para el TDAH entre los años 1980 al 2010, que quienes reciben tratamientos e intervenciones, ya sea farmacológicas, combinadas o de otro tipo, a menudo experimentan mejoras relevantes a largo plazo en comparación con quienes no lo reciben.

Cuando se utiliza de forma multimodal, las evidencias apuntan a que la combinación de tratamiento farmacológico y terapia especializada es beneficiosa, puesto que se conoce que el abordaje clínico médico con psicoestimulantes es el tratamiento de primera línea en adultos para el manejo agudo y crónico del TDAH (Adler et al., 2016). Por ello, la terapia combinada y específicamente, los resultados de la terapia cognitivo conductual, reducen de forma importante las alteraciones funcionales en los adultos (Abad-Mas et al., 2011; Antshel et al., 2008; Ramos-Quiroga et al., 2012; Roizblatt et al., 2003) y ayuda a afrontar la sintomatología refractaria de la terapia farmacológica en los adultos con TDAH (Ramos-Quiroga et al., 2006), reportándose mejoras en su calidad de vida en términos generales.

La terapia cognitivo conductual es una de las más utilizadas en los adultos, la cual de acuerdo con Rostain \& Ramsay (2006), implica considerar y generar una conceptualización en el que se van generando los aprendizajes a partir de la propia historia del sujeto, las creencias negativas, los esquemas resultantes y el comportamiento autodestructivo que las personas con TDAH han ido desarrollando a la largo de su vida. De igual forma es útil para el tratamiento de problemas funcionales, como son la procastinación, mala gestión del tiempo, la baja perseverancia y finalización de las tareas (Davidson, 2007).

La intervención combinada desde una mirada psicopedagógica, cobra relevancia entonces para el logro académico y el futuro desempeño laboral de los estudiantes universitarios con TDAH. Siendo vinculada a nivel científico con el éxito en el desarrollo de la autoeficacia en adultos con TDAH, puesto que quienes han sido sometidos a ella mejoran la confianza en sus capacidades para afrontar los desafíos de una manera eficaz y activa (Newark \& Stieglitz, 2010) y con mayor regulación. Así también, se ha visto un mejor desarrollo de las FE especialmente, en la planificación de la conducta, la toma de decisiones, la inhibición y la iniciativa.

\section{Método}

Dada la complejidad de la temática y la intención de este estudio de comprender la presencia y característica de los cambios que los participantes declaran desde un paradigma interpretativo, se ha seleccionado como método, el estudio de casos múltiple. Con el propósito de recoger y analizar en profundidad la naturaleza de un grupo de estudiantes universitarios desde la particularidad y singularidad de sus relatos y experiencias, para llegar a comprender tanto sus actividades, como su 
desarrollo en circunstancias importantes (Stake, 1998). Siendo esta metodología una amplia tradición en las ciencias sociales, que permite una comprensión exhaustiva y desde múltiples perspectivas de la temática de esta investigación (Simons, 2011). Surge entonces, la necesidad de considerar que por las características del diseño no siempre es posible extrapolar los hallazgos y conclusiones a una población general, debido a que se trata más bien de interpretaciones particulares con elementos comunes que permiten una mayor comprensión de las manifestaciones (Geertz 1987)

\section{Participantes}

Para el presente estudio, los participantes fueron seleccionados a través de un método polietápico. En la primera de ellas con un muestreo intencional, se seleccionan a 23 adultos puesto que cuentan con diagnóstico de TDAH. Son estudiantes y/o empleados de diferentes carreras profesionales de las áreas de la salud, ingeniería, ciencias sociales, ecoturismo e idiomas, de 4 universidades de la región de Valparaíso, con edades entre los 18 y 33 años.

En una segunda etapa de los 23 estudiantes, 6 han sido considerados para este estudio de los cuales 3 son hombres y 3 son mujeres, pues respondieron a los siguientes criterios: (a) presencia de diagnóstico de Trastorno de Déficit de Atención en la infancia o en la adultez, (b) estar con tratamiento farmacológico de al menos 3 meses, (c) estar cursando al menos el tercer semestre de educación superior, (d) presentar bajo rendimiento académico, (e) haber finalizado la totalidad de la fase de intervención psicopedagógica en tiempo estipulado. Las edades de estos participantes se ubican en el rango de 20 a 33 años. A continuación, se entrega una breve descripción de cada uno de ellos.

- Universitario 1, 20 años estudiante de 3er semestre de medicina, soltero, vive con sus padres, realiza acciones sociales y políticas en la universidad. Es diagnosticado con un TDAH en el tercer semestre de estudios y ha reprobado (suspendido) dos asignaturas (materias).

- Universitario 2, 33 años estudiante de 4to semestre de Ingeniería en Construcción, casado sin hijos, trabaja de día y estudia de noche, en la infancia presentó dificultades atencionales, por lo que recibió atención profesional por un tiempo sin mayores cambios en su desempeño. Ha reprobado tres asignaturas y dos de ellas por segunda vez.

- Universitaria 3, 22 años estudiante de 4to semestre de Nutrición y Dietética, soltera vive con sus padres, presenta importantes dificultades emocionales luego de presentar un cáncer óseo juvenil, ha sido diagnosticada con TDAH en el segundo semestre de sus estudios y ha reprobado 2 asignaturas, dos veces cada una.

- Universitario 4, 24 años estudiante de 9no semestre de Medicina, soltero, vive con sus padres, con un cuadro ansioso y presencia de tics permanentes. $\mathrm{Ha}$ recibido múltiples apoyos de profesionales externos por su diagnóstico de TDAH en la infancia y por sobre todo por sus dificultades a nivel emocional. $\mathrm{Ha}$ reprobado 4 asignaturas y una de carácter práctico.

- Universitaria 5, 20 años estudiante de 3er semestre de Odontología, soltera, vive con sus padres, practica deportes frecuentemente. Es diagnosticada con TDAH en el segundo semestre académico y ha reprobado tres asignaturas.

- Universitaria 6, 20 años estudiante 5to semestre de Ingeniería Civil Química soltera, vive con sus hermanas, dificultades emocionales por muerte de ambos padres en la infancia, es diagnosticada con TDAH en el 4to semestre de estudios y ha reprobado seis asignaturas, tres de ellas dos veces. 


\section{Instrumentos}

Para llevar a cabo esta investigación se usaron variados instrumentos y materiales tanto para la determinación de los niveles de desempeño de los participantes, como para el trabajo de intervención de sus funciones ejecutivas. Los cuales se describen a continuación asociados a sus etapas.

En la Fase de diagnóstico o evaluación inicial se aplicó una entrevista semiestructurada tipo anamnesis para el registro de antecedentes de desarrollo y aprendizaje, para conocer en profundidad su historial de vida en cuanto a salud, educación, relaciones sociales, familiares, como hábitos de estudio, alimentación, sueño, ocio, entre otros y una batería de evaluación multidimensional de las funciones ejecutivas y TDAH seleccionada para el efecto, la que contempla: Test de observación To Palabras-1 (Rosell, 1999), Test de Copia y de Reproducción de Memoria de Figuras Geométricas Complejas (Rey, 1999), Test de colores y palabras Stroop (Golden, 2005.), Pruebas de Método y Orden MO2 Forma 2 (Seisdedos Cubrero, 1997), Test de Memoria y Aprendizaje TOMAL (Reynolds \& Bigler, 2001), Test de Atención (Alcalde \& Sauras, 1982), Escala de estrategias de aprendizaje ACRA (Román-Sánchez \& Gallego-Rico, 2001 ), Test de Flexibilidad Cognitiva CAMBIOS (Seisdedos, 1994) y Test para la Evaluación de las Funciones Ejecutivas ANILLAS (Portellano \& Martínez-Aria, 2011).

En la Fase de ajuste e implementación de la intervención en cada uno de los casos se utilizaron diversos recursos pedagógicos y psicopedagógicos en diferentes formatos gráficos, digitales y concretos, en la línea de juegos de inteligencia, bitácoras de autorreporte, actividades de desarrollo cognitivo extraídas del Programa de Enriquecimiento Instrumental de Reuven Feuerstein, estrategias de aprendizaje universitario en líneas de Bernard, 1999; Pozo \& Postigo, 1993; Pozo \& Monereo 1999, el Modelo 3P: Presagio, Proceso y Producto de Biggs, 2001, entre otros.

Todos ellos dentro de la propuesta central del modelo de FE "Tres Momentos para Aprender 3MA", el cual fue desarrollado para el efecto por las autoras de este artículo, el cual se describe brevemente a continuación con el siguiente diagrama:

Imagen 1. Propuesta de Tres Momentos para Aprender 3MA

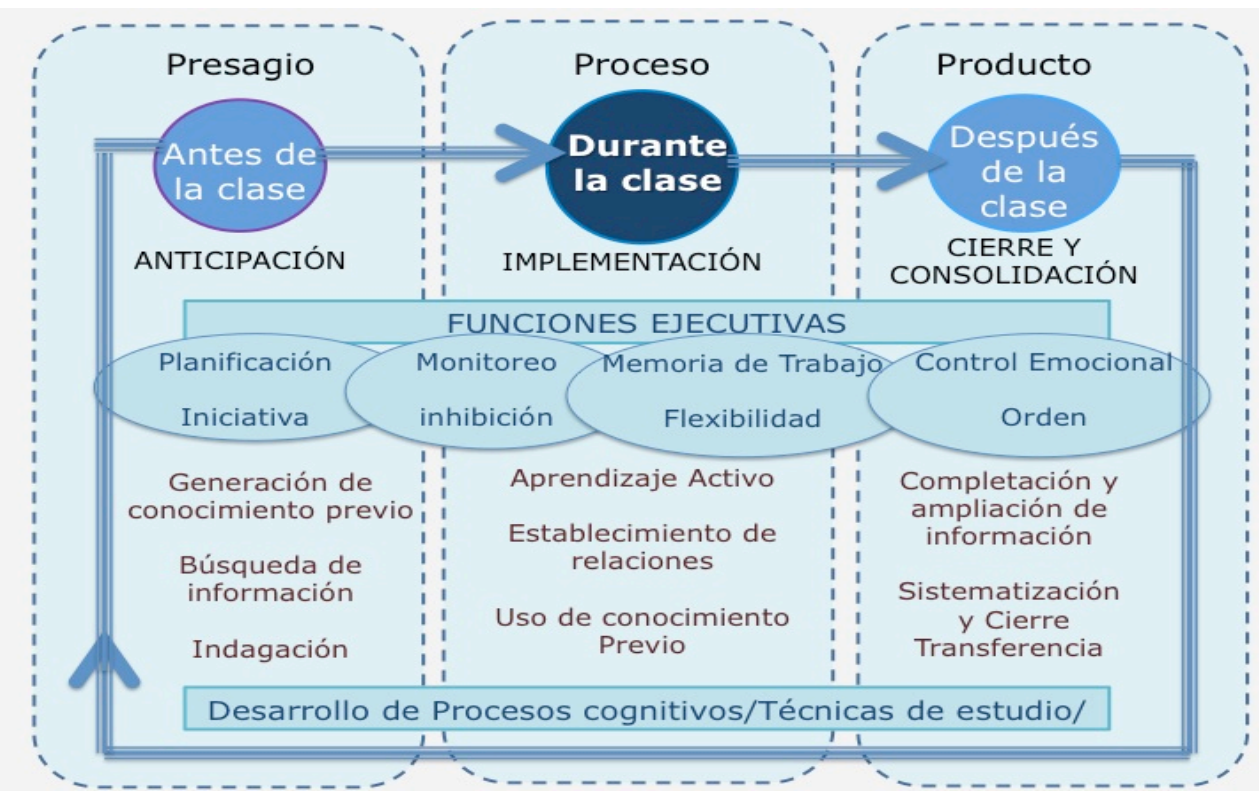


El modelo 3MA se sustenta en tres pilares fundamentales: a) desarrollo de las funciones ejecutivas; b) desarrollo de procesos cognitivos y c) desarrollo de estrategias de estudio y de aprendizaje. Lo anterior planteado en una estructura cíclica de 3 momentos en relación al actuar anticipado y consciente de un aprendiz activo. Tres fases que en un ciclo continuo de acciones buscan regular y estructurar el funcionamiento de un estudiante que asiste a clases y que debe responder a requerimientos diarios en su rol de aprendiz de educación superior.

Finalmente en la Fase de evaluación del cambio se utilizó principalmente una entrevista cualitativa en profundidad para cada caso en un marco de relato de vida, que constituye el insumo central de este artículo. La cual se realizó con el principal objetivo de conocer las valoraciones que hacían los sujetos con respecto a la experiencia vivida en la intervención con el modelo de funciones ejecutivas. Abordándose tópicos referentes al uso de las FE en su vida cotidiana y académica, tipos de obstaculizadores y facilitadores del aprendizaje, uso de estrategias efectivas de estudio, motivaciones, cambios, entre otros.

\section{Procedimiento}

En esta investigación el proceso de contacto e inclusión del estudiante en el estudio fue de tipo bola de nieve, pues la derivación de los estudiantes al proceso de intervención fue realizada por profesionales del área de salud mental, quienes realizan los diagnósticos especializados para la determinación de la presencia de un TDAH en sus pacientes a nivel privado y público en la región de Valparaíso. Es en este contexto que aquellos profesionales hacen las derivaciones al Instituto de Desarrollo Cognitivo IDCO de la ciudad de Viña del Mar, donde se completa el proceso de tratamiento multimodal con una intervención psicopedagógica especializada en el desarrollo de las funciones ejecutivas, del cual da cuenta esta investigación y que se describe en cuatro fases a continuación.

Fase de Selección de los sujetos. En esta fase se inició el proceso de selección de los estudiantes de educación superior derivados a IDCO. Se seleccionó inicialmente a 23 sujetos con diagnóstico de TDAH con bajo rendimiento académico que requerían una evaluación cognitiva integral y una intervención psicopedagógica. De ello 6 participantes finalmente fueron los seleccionados para este estudio porque cumplían con los criterios especificados en el apartado de sujetos.

Fase de Diagnóstico o evaluación inicial. En esta se llevó a cabo con los 23 sujetos, un proceso de identificación, determinación y constatación de los niveles de desempeño en cuanto a su funcionamiento ejecutivo, procesos cognitivos superiores, sus niveles de atención y concentración, autoconcepto académico, motivaciones y uso de estrategias de estudio. Lo anterior, por medio de dos acciones, la primera de ellas una entrevista semiestructurada tipo anamnesis, de una hora de duración en forma presencial con cada sujeto y luego la aplicación de una batería de instrumentos distribuidos en tres horas de trabajo individual y presencial. Tarea de gran relevancia, porque no sólo culminó aportando evidencia empírica en detalle sobre su condición de TDAH y sus desempeños en las funciones ejecutivas, sino que también permitió una mejor visualización de las posibles causas del bajo rendimiento académico.

Fase de Ajuste e implementación de la intervención a cada uno de los casos. Esta etapa estuvo destinada a generar e implementar una propuesta exhaustiva de intervención de las $\mathrm{FE}$ en los 18 de 23 participantes que aceptaron asistir voluntariamente. Tarea que implicó un proceso de revisión y reformulación de los materiales y actividades ya protocolizadas para estos efectos en IDCO, de forma de 
adaptarlas a las condiciones individuales de cada uno. De este modo se planteó una estructura común con ejes centrales basados en un Modelo de Funciones Ejecutivas denominado Tres Momentos para Aprender 3MA, pero con diferencias y ajustes a las particularidades de cada caso según las evidencias de la fase diagnóstica. Iniciándose finalmente un proceso de intervención individual de doce sesiones de trabajo con una duración de sesenta minutos cada una en una frecuencia semanal.

Fase de Evaluación del cambio. En esta última fase se realizó una entrevista, de carácter voluntaria, abierta y en profundidad a los estudiantes que habían sido intervenidos y habían finalizado la totalidad de la intervención en las fechas estipuladas. De un total de dieciocho sujetos que tomaron la intervención, once finalizaron en el tiempo propuesto, debido a que los siete restantes habían presentando irregularidad en la asistencia. No obstante solo ocho aceptaron realizar la entrevista final, y de estos se presentaron seis. La entrevista se llevó a cabo en forma presencial y con una duración aproximada de una hora cronológica. Con este procedimiento se intencionaba la explicitación por parte de los sujetos, de las estrategias y procedimientos que habían o estaban implementando en su desempeño académico y personal, principalmente las que habían sido intencionadas en el modelo de intervención propuesto para ellos. Desde aquí se obtuvo como resultado un marco descriptivo de la situación final de los estudiantes, en cuanto a sus cambios y las valoraciones que hacían sobre si mismos.

\section{Análisis de datos}

La información obtenida en cada uno de los casos a partir de las entrevistas fue transcrita y analizada por medio de análisis de contenido, de forma de lograr su segmentación y determinar las temáticas que emergían de cada una de ellas. Llevándose un proceso de pre análisis como primer intento de organización de la información, para luego definir las unidades de análisis seleccionadas, establecer reglas y códigos de clasificación, para lograr elaborar categorías que permitieron ordenar y clasificar definitivamente el contenido, logrando finalmente la integración final de los hallazgos (Cáceres, 2008). Todo lo anterior, con el propósito de identificar los factores, tópicos y variables comunes, desde una perspectiva inductiva por medio de una codificación inicial (Simons, 2011), lo que permitió focalizar las implicancias y valoraciones que hacían cada uno de los seis sujetos al finalizar el proceso de intervención.

\section{Resultados}

Para lo anterior, se sistematizó en un principio los resultados obtenidos en la etapa inicial de evaluación de las FE, niveles de atención y concentración, así como hábitos y estrategias de estudio, en cuanto a los percentiles obtenidos en el grupo total de 23 sujetos y los 6 sujetos seleccionados, lo que se visualiza a continuación:

A continuación se presentan las categorías (temáticas) de las 6 entrevistas en profundidad en relación a sus cambios, valoraciones y discusiones en cuanto a su desempeño después de la experiencia de haber participado del modelo 3MA 
Imagen 2. Representación de categorías emergentes

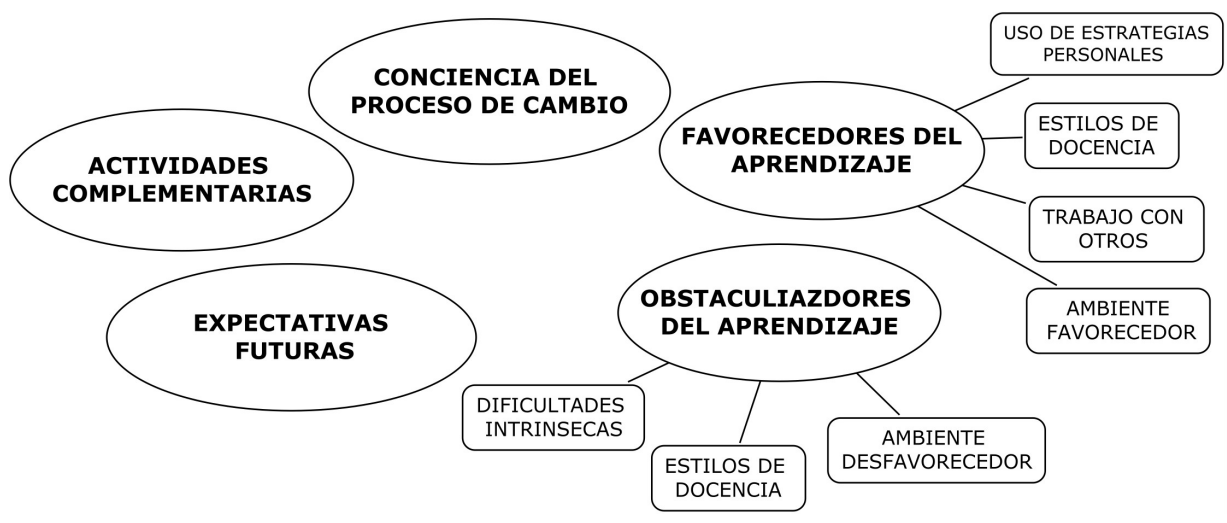

\section{Conciencia del cambio}

En esta categoría se consideran las valoraciones positivas que hacen los sujetos sobre el cambio que han evidenciado posterior a la intervención. Las temáticas que emergen dicen relación a como ha cambiado su estilo de vida, sistemas de estudio, describen las modificaciones en sus hábitos y rutinas. Referenciando reformas importantes en ellos mismos, en cuanto a las FE de iniciativa, automonitoreo, orden, control emocional, entre otras. También se evidenciaron logros en la toma de decisiones, en la iniciativa que ahora presentan frente al ámbito académico, al orden de sus materiales personales y de estudio:

Universitaria 6: uf cambié, ahora ya tengo como mi horario, yo sé que si me acuesto a las 3 ya no voy como que a rendir mucho al otro día, aparte no me va a ir bien en las pruebas, entonces como que igual pongo un límite, máximo, si es que tengo prueba al otro día, máximo. A la 1, pero no, no paso más de eso.

Universitaria 5: yo creo que ahora estoy más organizada, y que, no sé, yo creo que en ese momento que me había ido como tan mal, que no estaba, como que estaba desordenada, entonces como que no tenía como las prioridades como bien, ahora soy diferente, muy diferente.

Universitario 4: era súper estricto y súper rígido en mis estructuras de pensamiento $y$ en mis estructuras de armar cosas, y hasta de relacionarme con la gente y ahora me pase al otro lado, (riendo) estoy demasiado relajado, pero mejor, el cambio es bacán (muy bueno).

Universitario 1: ahora es más fácil organizarme, logro hacer asociaciones entre las cosas que estoy aprendiendo, eso me ayuda que el aprendizaje sea más lógico, porque lo asocio en lo clase y después no se me olvida.

Universitaria 5: ya después con el tiempo uno después se va haciendo consciente de tiene que estar concentrado en clases y por eso que uno va captando todo el proceso de la explicación que está haciendo el profesor de lo que sea.

Universitaria 6: yo también percibo un cambio en mí, ahora no me cuesta ponerme a estudiar, si me tengo que poner a estudiar, me pongo a estudiar $y$ listo, no pierdo el tiempo, No, no es difícil para mí ponerme a estudiar, de 
hecho ya tampoco me cuesta, yo estudio hasta las 12 de la noche cuando necesito hacerlo y después me despierto a las 5 de la mañana, para seguir estudiando.

\section{Expectativas futuras}

Tópico muy relacionado a lo que implica la proyección futura, situación que previo a su proceso de intervención carecía de efectividad, pues sus decisiones eran muy mediáticas, como dar solución a temas emergentes, como por ejemplo estudiar para rendir, dormir por estar cansado, evadir las responsabilidades académicas por baja motivación, etc. Desde las entrevistas fue posible visualizar predicciones y proyecciones positivas que traspasaban las necesidades inmediatas de solo rendir por cumplir, sino para aprender más, disfrutar y conseguir metas específicas relacionadas con su desarrollo profesional y personal:

Universitario 4: Quiero este año, haber terminado con excelentes resultados en el internado, haber aprendido mucho y darle para último año no más, de ahí, una vez terminado trabajar como médico.

Universitaria 6: primero, sacar el título de ingeniera, trabajar en Codelco y conseguir un buen puesto ahí. A mí me gusta más la parte que es ambiental, me dedicaría a medioambiente para generar conciencia y cambio en Chile.

Universitaria 3: me gustaría saber harto ahora para que cuando termine, partir en un consultorio municipal, después en una clínica privada y tener mi consulta.

Universitario 1: siempre he pensado, que no me gustaría salir y pensar altiro (inmediatamente) en especializarme, no, no es eso lo que me interesa, me interesaría, irme a un lugar lejano en Chile que se necesite un médico, en el que pueda lograr, como.., un cierto impacto quizás.

\section{Actividades complementarias}

La consideración de poder hacer varias cosas a la vez por medio de la planificación y la organización del tiempo, surge como una nueva estrategia de funcionamiento personal que les es efectiva y que ha favorecido el manejo de sus estados ansiosos, especialmente cuando los periodos académicos son más demandantes para ellos. Este aspecto es relevante pues alude a las FE de planificación que han desarrollado, a la inhibición como estrategia que les ha permitido rechazar distractores y poder retomar sus deberes aunque sean varios a la vez. Al poder llevar una mejor calidad de vida, de forma más consciente, ordenada y sobre todo no solo orientada a la realización de deberes académicos sino también a la vida diaria.

Universitario 1: jahora hago hasta deporte!, es como entrenamiento, es parecido al TRX, muchas veces digo como, ohh debería estar estudiando, pero digo no, si no voy, voy a después pensar pucha, no fui!, así que voy no más y después sigo estudiando tranquilo.

Universitaria 5: salgo a correr..., ahora ya no me he metido mucho al gimnasio, pero salgo a correr en las mañanas, ehhh me gusta también eh, ir a bailar, ir al cine....es que me organizo bien, pero a veces cuando tengo pruebas y todo, no lo hago, y ahí priorizo. 
Universitario 2: Hay veces que el fin de semana me dedico hacer nada, sábados y el domingo también nos levantamos tarde, de estudiar estudio por la tarde tranquilo sin culpa, así me organizo, la verdad es que últimamente hemos estado practicando patín y puedo hacer todas las cosas.

Una temática relevante que ha surgido desde las voces de los entrevistados apunta a que ellos ahora son conscientes de que hay factores que les son favorecedores para su proceso de aprendizaje y otros que por el contrario lo dificultan. Sin embargo la relevancia de los hallazgos está en que ahora los conocen, los pueden modificar y son conscientes de que dichos factores que intervienen positiva o negativamente en su aprendizaje no son solo externos, sino también de carácter personal.

\section{Favorecedores de su proceso de aprendizaje}

En esta categoría las temáticas que emergen están relacionadas con el uso de estrategias personales de funcionamiento, el ambiente de aprendizaje, los estilos docentes y el trabajo con pares.

a) Uso de estrategias personales de funcionamiento: Los participantes hacen referencia al uso de estrategias personales que posterior a la intervención le son efectivas en el estudio y en su funcionamiento general. Las cuales inciden en la forma en toman las decisiones para resolver situaciones problemáticas a las que se ven enfrentados a nivel académico, aludiendo al uso de FE de planificación, automonitoreo, iniciativa, control emocional, cambio e inhibición en su actuar como aprendiz de educación superior:

Universitaria 6: primero, me siento adelante, ojalá sin ninguna amiga que me esté hablando, ni nada de eso. Y antes de clases me preparo ahora, o sea, le pregunto al profesor el tema que vamos a ver en la clase siguiente, y lo estudio.

Universitaria 6: Lo empecé a hacer este año con usted, usted me enseñó esas técnicas, después de la clase hago un resumen cuando ya entendí la materia, hay algo que no entendí, no lo hago y lo anoto y se lo pregunto al profe a la otra clase. Para que después al estudiar sea más fácil y no tener que leer de nuevo todo el libro, o el cuaderno.

Universitario 1: siempre que podía, intentaba leer todo lo que se iba a ver en la clase, entonces leía un poco, para ir preparado con eso y si me doy cuenta de que es mucho mejor anticiparse a la clase, porque se toman mejores apuntes y uno, como que ya está pensando en lo que te están enseñando, relacionando.

Universitaria 5: ¿Cómo hacer esquemas? porque encuentro como que me facilita como aprenderme las cosas, porque tengo como más ordenado, aparte tengo más memoria visual..., entonces me acuerdo bien de eso y como empezar a usar colores y cosas así, como que, cosas como más establecidas, como que me ayudan.

Universitario 2: el tema de la agenda, finalmente uno se ordena con eso, los calendarios, finalmente ayuda, y ayuda, en especial cuando tu estás con muchas cosas, porque hay cosas que se te van finalmente, en el trabajo me pasa, que a veces estoy haciendo lista, check list, y voy viendo.

Universitario 1: enfocarme en lo que tenía que hacer, porque ese es mi problema, y aplico lo que también usted me enseñó, que si se me viene algo a 
la mente que tengo que hacer, lo anoto a un lado en el cuaderno, y así despejo en la mente algo que al finalizar lo veo si era importante.

Universitario 4: me sirvió la organización de mi tiempo..., y que, pase por etapas primero súper organizado, te acuerdas cuando hicimos ese horario súper estructurado, el calendario con los meses, después me hice horarios de estudio y después me di cuenta que me estaba estresando caleta con eso, que era súper obsesivo con el tema, entonces después aprendí a relajarme y eso fue el cambio más grande.

Universitario 1: Yo ahora tengo, esquemas de colores, para tratamiento, para diagnóstico, para síntomas, para presentación clínica, mentalmente me hago una red de esquemas, el glosario que me enseñaste y ahora es súper amplio y se va ampliando con el tiempo.

Universitario 4: lo de los 5 conceptos, la he ocupado principalmente con el mismo esquema, de presentación clínica, y saco 2 palabras y con eso tengo y a veces se hace el diagnóstico así de simple, porque aparecen 2 cosas en un paciente y yo digo estas 2 palabras, estos 2 diagnósticos y ahí armo todo el cuadro y ahí, después ya saco los conceptos en profundidad,

b) Ambiente favorecedor. Las apreciaciones se orientan a como han tomado conciencia de la necesidad de hacer modificaciones en el momento de aprender en clases, sobre todo controlando de factores ambientales distractores que pueden interferir en su aprendizaje. En este sentido dan cuenta de las modificaciones que llevan a cabo, evidenciando el uso de FE de automonitoreo, autocontrol e iniciativa.

Universitaria 6: el teléfono ahora lo controlo yo, si no necesito comunicarme urgentemente con mi familia le saco la WIFI, solo lo tengo en la mesa para ver la hora por ejemplo, en las salas de la universidad no hay relojes, con mi cuaderno al frente y pongo atención,

Universitaria 5: necesito ahora primero, sentarme en la primera o segunda fila, es lo que más me sirve, y otra cosa es sentarse con gente que quiera poner atención, antes me sentaba y conversaba harto.

Universitaria 3: ahora siempre trato de sentarme adelante, porque de atrás imposible escuchar, se distraen mucho con el celular y todo eso. Trato siempre, de, escribir, apuntes, y los PowerPoint..., a veces los veo antes de clases, y cuando llego a la casa, también, trato de hacer mi resumen de la clase que vi.

c) Estilos de docencia como un favorecedor. Un aspecto relevante que emana son las implicancias que tiene para ellos como un potenciador el estilo de docencia, la relación que desarrollan con sus profesores. Lo que impacta a su juicio en su motivación y en la implicancia en las tareas académicas. Situación que presentaba una valoración negativa en el momento de ingreso a la intervención, en donde la docencia era vista como una barrera y causal principal de su bajo rendimiento académico.

Universitario 1: uno se da cuenta cuando el profesor está interesado, uno nota eso, uno nota eso y hay un profesor, que es excelente en todo sentido, que me motiva mucho a estudiar, motiva mucho su forma de ser. 
Universitario 4: aparte de hacer clases súper completas manda todos los apuntes también antes, pero bueno ahí está él... es súper buen docente, está muy disponible a recibir consultas y una vez cuando yo estaba terminando tercer año yo quede con una duda de un texto que nos mandó y le mande un correo electrónico preguntándole por el texto para buscarlo y me lo mandó, así que es muy preocupado por sus alumnos cuando quieren aprender.

Universitario 1: algunos profesores que tuve en los ramos médicos introductorios vi un compromiso y vi orden, yo pensaba lo mismo que, por la misma razón que yo estaba ahí, estoy estudiando esto..., entonces por eso me motivó más.

La organización previa, el orden de las materias, así como la coherencia en la dinámica de la clase por parte de los docentes con estilos de enseñanza definidos y coherentes, surgen como facilitadores en los participantes para llevar a cabo un aprendizaje más afectivo, regulado y con mayor motivación, evidenciando un impacto en las FE e planificación, cambio y control emocional.

Universitaria 3: me gusta que sean más ordenados, porque así yo entiendo mejor, si por ejemplo, al principio me dan un programa, me dicen: - estas van a ser las fechas de pruebas, estos van a ser los libros que vamos a utilizar, yo también me programo, me voy planificando para estudiar con tantos días para esas pruebas.

Universitaria 6: me he dado cuenta que me gusta cuando los profes se nota que saben el contenido, llegan con la clase preparada y hacen muchos esfuerzos en la clase para que aprendamos, mandando guías, haciendo más pruebas de las que dice el reglamento. Porque aunque sea pesado yo estudio más así.

Universitario 2: aprendo si ella me da una explicación más o menos clara, pero breve, así yo después puedo consultar en los libros y profundizar más el tema, no necesito que me pase todo, tal cual como diga el libro, pero que me de una idea así como general desde lo que ella entiende, es mejor para mí.

Valoran positivamente la transferencia a la vida cotidiana, a los espacios laborales actuales y futuros, puesto que a su juicio ello les permite vincular los contenidos con experiencias significativas, favoreciendo la memorización de los tópicos revisados en clases:

Universitario 4: este profe hace como mini recreos en la clase, como contar una anécdota, que tampoco es una hora, son dos minutos o menos, sí. Hacía ejemplos de la vida cotidiana..., igual, a uno, le.., como le quedaba esa información en la cabeza, y recordaba al momento de estudiar, esos ejemplos.

Universitario 1: yo creo que cuando nos presentan casos clínicos, es como más mejor, lo mejor es cuando nos ponen casos clínicos y aprender en cosas que son más o menos reales y cuando nos presentan casos reales que han tenido los mismos docentes,

Universitaria 3: cuando usan como un enganche con cosas reales, es súper bueno a uno le quedan las cosas grabadas, hasta uno se acuerda, algo, jah 
de verdad que el profesor dijo esto! que le había pasado tal anécdota, que él había viajado y se acordó de esto, eso sirve.

d) Trabajo con otros. Emerge como un tópico importante pues los sistemas de trabajo colaborativo, no eran positivamente valorados por los participantes previo a la intervención, aludiendo que eran espacios con baja efectividad para su estudio personal, que eran siempre asistemáticos y no muy satisfactorios. Sin embargo, a partir de sus apreciaciones surgen cambios en sus valoraciones, ahora ven como positivo el trabajar académicamente con otros, pero con ciertas regulaciones y condiciones, lo que evidencia un cambio a nivel de su control emocional, iniciativa y sobretodo inhibición en la toma de decisiones:

Universitario 1: creo que también y me he dado cuenta de que, mis amistades son todas distintas obviamente, entonces, si me siento con un muy buen amigo, o una persona que es buena para la chacota (hacer bromas), probablemente, me voy a desconcentrar más, en cambio, si me siento generalmente con mujeres ahora, así lo estoy haciendo, que están como más enfocadas y no desconcentran pensando en tonteras y me ayuda harto.

Universitario 2: Empiezan a agarrarte y agarrarte y haces lo mejor posible y te dedicas y estudias con los compañeros, porque eso ayuda mucho, el ir, juntarse, usar la pizarra, ayuda bastante, porque es bueno para todos. Otra situación también es el tener yo creo que, un grupo de estudio bueno y que todos pongan de su parte.

Universitario 4 : bueno es que tengo un grupo de estudio, o sea, no sé si de estudio, porque en verdad no es tanto lo que estudiamos juntos, pero conversamos la materia y hacemos súper buen equipo, en el hospital incluso preparamos juntos temas y los casos. Yo voy con ellas, son un grupo de amigas.

\section{Obstaculizadores del Aprendizaje}

Los participantes de la misma forma que determinan factores favorecedores a su proceso de aprendizaje, refieren un conjunto de valoraciones hacia variables que se les convierten en una barrera para llevar a cabo sus labores académicas con éxito. Estos obstaculizadores se relacionan con dificultades intrínsecas, los estilos de docencia a los que se ven enfrentados y ambientes académicos desfavorecedores.

a) Dificultades intrínsecas. Conciencia de las dificultades personales que estos evidenciaban antes de la intervención y que son atribuidas como posibles causales explicativas de su bajo rendimiento académico, las cuales son descritas como baja comprensión de las temáticas abordadas, falta de hábitos de estudio, dificultades en la resolución de evaluaciones y exámenes, baja participación en clases y en proceso formativo en general, inseguridad y pérdida de atención en clases.

Universitaria 6: mi hermana ya había visto que no entendía, en primero puedo decir que no estudie, pero en segundo mi hermana me veía tratar de estudiar y también veía que yo me desconcentraba muy rápido, o que no se , que me mandaban a comprar el pan, yo llegaba con todo lo opuesto que me decían y yo no lo hacía intencionalmente y mis hermanas pensaban que ya eso no era normal. Algo tenía que no me concentraba lo suficiente. 
Universitaria 3: para mí era difícil entender, yo entendía, pero la prueba me costaba porque los ejercicios eran muy complicados y nosotras, hacíamos grupos y hacíamos ejercicios de pruebas antiguas, y todo, pero aun así, no sabía a que enfrentarme en la prueba.

Universitario 4: lo que me interfería en clases, o sea un poco, porque yo igual me desconcentraba rápido en la clase(ríe), era el sueño un poco, como que, es que poco, siempre me ha pasado, como que, en los primeros ratos como que presto mucha atención, pero después obviamente como que el pensamiento se me va, y de ahí no me pierdo.

Universitario 2: lo que si me daba a veces, no sé si lata, no sé cómo definirlo, no sé si vergüenza, pero yo creo que es eso, inseguridad, de volver atrás porque estaba súper perdido y el profesor me quedaba mirando.

Universitaria 6 :jla estrategia del Antes no la usaba nada y las de Después tampoco!. Nooo, yo a veces, no sé, en primero segundo año, me sentaba al final de la clase, no entendía nada en la clase, porque me distraía con mis compañeros, siempre hay algún bullicioso por ahí.

b) Estilos de docencia. El aprendizaje de un estudiante con diagnóstico de TDAH la vinculación y la emocionalidad son factores esenciales en el proceso de aprendizaje pues les permite focalizar y atender a la información que se entrega. En este sentido las valoraciones que hacen los sujetos en este aspecto son variadas, sin embargo, hacen hincapié en que los interfiere bastante pedagógicamente el que un docente no presente una estructura y organización de sus contenidos, o que no sea empático, ni esté llano a responder a sus dudas, o que no se muestre entusiasmado con su ejercicio docente, o que simplemente no lleve una coherencia en su discurso en las clases. Este último punto concentra más opiniones, pues se evidencia que cuando los docentes en sus discursos de clases cambian el tema central y van a hacia experiencias no vinculadas con el mismo, los participantes tienden a perder el foco de atención y aumentar su nivel de distractibilidad en el aula, sumado a que les dificulta mucho retomar el sentido de la temática que se estaba abordando.

Universitaria 6: O sea que, cuando estamos hablando del tema de cálculo y que después se iban a otro tema que no tenía nada que ver con cálculo, entonces como que me desconectaba de la clase, me perdía y como que me costaba mucho más aprender.

Universitario 4: lo que pasa es que hay profes que son muy desordenaos, y eso ya me molesta, cuando son desordenaos y pierdo la atención rápidamente y la pierdo en serio, de hecho pienso que es mejor que la pierda porque me desordenan a mí, entonces prefiero estudiar aparte eso y no enredarme con lo que está diciendo el profe.

Universitaria 5: que el profesor da la clase y entrega de a poco la información, se me dificulta un poco más. Porque si yo tengo la clase el día miércoles, lo lógico es que el profesor la subiera ese mismo día miércoles, o durante ese miércoles, era lógico, porque había veces en que, el profe lo entregaba el día martes de la próxima semana y ahí se genera un, un desorden....finalmente se me va acumulando materia para el final porque no la tienes.

Universitaria 3: algunos profesores, no se veían así como motivados, porque venían como con mala gana, a veces, o se veía que era como serio y uno le 
preguntaba: - profe, ¿nos puede pasar el power? - y nos decía no porque lo voy a subir después, pero no lo subía y así pasaba una semana y le decías, hasta que lo subía a última hora.

Universitaria 6: me gusta y me gustaba que solo se centraran en la clase, o sea, no me gustan esos profes que mientras están haciendo la clase hablan de su vida, del hijo, del nieto y no pasan la materia. Y después igual entraba en las pruebas, entonces, me gusta que se centre, por ejemplo si estamos en clases de cálculo, solo hablemos de cálculo, igual siempre hay un tiempo para un relajo, o sea que la mayor parte del tiempo sea cálculo y que la profe pregunte si quedaron dudas, no que hable de otras cosas.

c) Ambiente desfavorecedor. En este aspecto las valoraciones hacen referencia al contexto físico y relacional donde se llevaban a cabo los procesos de aprendizaje, pero el cual podía transformarse en un ambiente que a ratos obstaculizaba el aprender, sobre todo a los participantes que evidenciaban dificultades para regular su atención, concentración y principalmente las funciones de automonitoreo y autorregulación.

Universitario 1: Sí el aire, sí..., si ya estaba muy encerrado el ambiente, me desconcentraba y empezaba a pensar en eso, en que quiero abrir una puerta, quiero abrir una ventana y empezaba a pensar, quizás hay gente que le va a dar frio y no la abría... y así pasaba mucho rato.

Universitaria 3: teníamos 2 profesores para un mismo ramo y eso nos perjudicó a todos, igual fue fome (aburrido) eso, porque éramos muchos y como no había espacio ni más salas y los profesores que eran para 2 secciones y se iban a una sala y a otra, entonces semana por medio había un profesor distinto.

Universitario 4: porque como es conocido por muchos acá en mi carrera en la universidad, es que cuarto año es, casi imposible compatibilizarlo con la vida porque entras muy temprano a hospital, después de hospital que hasta media jornada hay clases hasta las ocho de la tarde, entonces estar de ocho a ocho y después estudiando, no tiene tiempo ni para respirar ese es el problema, pero de este año no mas.

Universitaria 3: al principio no me gustaba realmente la $U$, ahora está distinto todo, porque como es un solo edificio tu ves gente de otras carreras, pero, antes era separado en otros lugares era un desorden todo.

\section{Discusión}

La intervención oportuna en los procesamientos cognitivos y en el desarrollo de las funciones ejecutivas en estudiantes universitarios que presentan un diagnóstico de TDAH con bajo rendimiento académico, ha evidenciado ser una estrategia efectiva para lograr cambios relevantes en su desempeño, reflejado en mejores calificaciones, la aprobación efectiva de asignaturas (materias) rendidas con anterioridad y un cambio evidentemente positivo en su calidad de vida. Lo anterior como consecuencia de la implementación de un modelo multidimensional de intervención psicopedagógica focalizado en estrategias de desarrollo y potenciación de las funciones ejecutivas, que buscaba intencionar en los aprendices, estrategias de anticipación, predicción, planificación, monitoreo, regulación de la propia conducta, autoconcepto académico adecuado y por sobre todo conciencia de sus potenciales y dificultades. Lo que 
favoreció el que estos aprendices con bajo rendimiento académico sumado a bajas expectativas personales, vivenciaran la experiencia positiva en la que el contar con herramientas específicas de funcionamiento y tomar decisiones adecuadas (condición no inherente en quienes poseen un TDAH) les permite desempeñarse de forma óptima y regulada en los diferentes contextos que los rodeaban

Así también la visualización positiva de sí mismos, como estudiantes efectivamente capaces de rendir y compatibilizar la vida académica con la personal a través de acciones planificadas, metas previamente planteadas, orden y organización de sus materiales, así como procesos de inhibición, automonitoreo y control de su conducta, les permitió conocerse y valorarse a sí mismos como personas que aun siendo poseedores de una condición diferente de aprendizaje como era su diagnóstico de TDAH, no los imposibilitaba de obtener buenos resultados en los desafíos actuales y futuros.

Es relevante destacar que posterior a la intervención los estudiantes identificaron de forma precisa tanto elementos favorecedores como barreras que impactaban su aprendizaje. Condición que les permitió entonces, el poder potenciar los facilitadores y por el contrario disminuir y/o enfrentar las barreras, evidenciando con ello un autoconocimiento y autorregulación en sus acciones. Además la experiencia de aprendizaje autorregulado les favoreció el enfrentarse de manera más óptima a las exigencias de la educación superior.

Si bien las características de cada participante eran diferentes, parte de los resultados encontrados son similares a los hallados por otros investigadores (Davidson, 2007; Newark \& Stieglitz, 2010; Lavigne \& Romero, 2010), principalmente en la relevancia de la intervención oportuna en adultos con TDAH. En esta línea la terapia combinada sigue siendo una estrategia efectiva en el abordaje del TDAH en los adultos, esencialmente para aquellos que llegan a la adultez desconociendo su diagnóstico y consultan por problemáticas de carácter emocional, ya sea por altos niveles de estrés o bajo rendimiento académico.

Las similitudes aparecen también, en la metacognición de sus propios cambios y en la efectividad de los mismos, por medio de la identificación y consideración de facilitadores de su desarrollo personal, social y académico los que les permitieron enfrentar nuevos desafíos en el contexto universitario actual. En concordancia con lo propuesto por Newark \& Stieglitz, (2010) quienes plantean que si los adultos con TDAH en sus terapias se identifican y reconocen sus talentos y potenciales, les permite la generación de creencias positivas sobre si mismos y sobre las propias capacidades. Lo que podría mejorar las habilidades de afrontamiento y romper el círculo vicioso de la valoración negativa que en ocasiones los caracteriza.

Coincidente con Davidson, (2007), la identificación positiva de las condiciones ambientales de sus espacios formativos y el trabajo con pares podían ser una instancia real de promoción de sus aprendizajes, porque el reunirse y formar equipos de estudio requería ahora el poseer autorregulación, objetivos y metas definidas hacia la colaboración, el aprendizaje mutuo y al logro académico. Puesto que el desarrollo de habilidades de autocontrol y el uso de la reestructuración del medio ambiente pueden ayudar a incorporar más estructura, rutinas claras y organización en la vida diaria.

En esta misma línea los estilos de docencia a los cuales se veían enfrentados fueron valorados por los participantes de forma dual, por un lado como agentes promotores de un aprendizaje consciente y activo, pero por otro como reales interferentes para sus 
motivaciones intrínsecas, su iniciativa y su compromiso como un aprendiz autorregulado de educación superior.

Por el contrario, el uso de técnicas específicas de estudio, de planificación, de manejo del tiempo, control y organización, emergen como estrategias concretas y asequibles. Pues cuando los participantes declaran haberlas implementados, valoran positivamente el llevar a cabo más de una actividad a la vez y cumplirla en su totalidad, sin perder el rumbo de la tarea ni la eficacia de la misma. Del mismo modo, el control ejecutivo y la autorregulación emergen como funciones ejecutivas fundamentales para solucionar situaciones problemáticas y complejas en la actualidad, sin embargo estas no eran visualizadas antes de iniciar su intervención psicopedagógica.

\section{Conclusiones}

EI TDAH es un trastorno neurobiológico que estará presente lo largo de toda la vida de las personas que lo poseen, generándoles desafíos complejos y significativos para ellos, sobre todo en la adultez. Desafíos que demandan a un estudiante de educación superior poseer un adecuado desarrollo de sus funciones ejecutivas para la resolución de situaciones complejas y el logro de las exigencias que este tipo de formación conlleva.

Es por ello, que la intervención en una modalidad combinada con aprendices adultos con TDAH en base a un modelo específico de FE como es el 3MA utilizado en este estudio, resulta ser una decisión acertada para dar un abordaje integral a las necesidades de apoyo que le emerjan en este contexto de aprendizaje. No obstante es necesario enfatizar que la efectividad de esta estrategia es posible en la medida que el foco no esté en atribuirle todo el valor a la terapia farmacológica, sino en preponderar desde la perspectiva cognitiva conductual el desarrollo de un aprendiz autorregulado, autónomo y por sobre todo consciente de sus acciones. Favoreciendo en ellos una estructura de funcionamiento desde la perspectiva que es necesario anticiparse a los eventos académicos futuros (momento antes de la clase), participar de forma activa en las situaciones que se vivencian (momento durante la clase), para finalmente consolidar y cerrar lo aprendido (después de la clase).

Considerando la necesidad de desarrollar y potenciar en los estudiantes, por medio de la intervención psicopedagógica, en primer lugar la flexibilidad cognitiva necesaria para la elección y uso de metas como de estrategias; en segundo lugar la iniciativa especialmente en la generación de una participación espontánea en clases de forma que estos se involucren reflexiva y estratégicamente en las instancias de aprendizaje; y en tercer lugar la anticipación y automonitoreo para enfrentar los desafíos que implica la educación superior como meta general, pero también el ser previsores de las demandas emergentes y cotidianas de sus asignaturas (materias) implementando de forma anticipada acciones de revisión y conocimiento de los contenidos a abordar en sus clases.

Finalmente, la implementación del modelo 3MA implicó cambios evidentes en sus desempeños y desarrollos, de los cuales los estudiantes fueron conscientes en la medida que iban implementando las estrategias aprendidas en sus contextos familiar, académico y social. Evidenciando en sus relatos una modulación de su pensamiento, de su conducta y por sobre todo de su motivación. Reflejada en la eficaz toma decisiones, en la consideración de diferentes alternativas, en el compromiso además de la responsabilidad en su propio proceso de aprendizaje, evidenciando una actitud reflexiva y crítica. Pero fundamentalmente, desde una perspectiva positiva en cuanto a 


\section{su condición de aprendiz con TDAH, destacando sus propias fortalezas por sobre sus dificultades.}

\section{Referencias}

Abad-Mas, L., Ruiz-Andrés, R., Moreno-Madrid, F., Sirera-Conca, M., Cornesse, M., Delgado-Mejía, I. D., \& Etchepareborda, M. (2011). Entrenamiento de funciones ejecutivas en el trastorno por déficit de atención/hiperactividad. Revista de neurología, 52(1), 77-S83.

Adler, L. A., Solanto, M., Escobar, R., Lipsius, S., \& Upadhyaya, H. (2016). Executive Functioning Outcomes Over 6 Months of Atomoxetine for Adults With ADHD Relationship to Maintenance of Response and Relapse Over the Subsequent 6 Months After Treatment. Journal of Attention Disorders, 1087054716664411.

Alvarado, I. R., Vega, Z., Cepeda, M. L., \& Del Bosque, A. E. (2014). Comparación de estrategias de estudio y autorregulación en universitarios. Revista electrónica de investigación educativa, 16(1), 137-148.

American Psychiatric Association. (2013) Diagnostic and statistical manual of mental disorders, 5ed. Arlington, American Psychiatric Association.

Antshel, K. M., Faraone, S. V., Maglione, K., Doyle, A., Fried, R., Seidman, L., \& Biederman, J. (2008). Temporal Stability of ADHD in the High-IQ Population: Results From the MGH Longitudinal Family Studies of ADHD. Journal of the American Academy of Child \& Adolescent Psychiatry, 47(7), 817-825. https://doi.org/10.1097/CHI.0b013e318172eecf

Aragonès, E., Piñol, J. L., Ramos-Quiroga, J. A., López-Cortacans, G., Caballero, A., \& Bosch, R. (2010). Prevalencia del déficit de atención e hiperactividad en personas adultas según el registro de las historias clínicas informatizadas de atención primaria. Revista española de salud pública, 84(4), 417-422.

Arias, A. V., Rodríguez, S., Cabanach, R. G., Pérez, J. C. N., \& Rosário, P. (2009). Diferencias en rendimiento académico según los niveles de las estrategias cognitivas y de las estrategias de autorregulación. Summa Psicológica UST, 6(2), 31-42.

Barkley, R. (2009) Avances en el diagnóstico y la subclasificación del trastorno por déficit de la atención /hiperactividad: qué puede pasar en el futuro respecto al DSM-V. Rev Neurol. 48 (sup/ 2), 101-106.

Barkley, R. A. (2011). Is executive functioning deficient in ADHD? It depends on your definitions and your measures. The ADHD Report, 19(4), 1-9.

Barkley, R. A. (Ed.). (2015). Attention-deficit hyperactivity disorder: A handbook for diagnosis and treatment. Guilford Publications.

Barragán Bech, R., Lewis Harb, S., \& Palacio Sañudo, J. E. (2007). Autopercepción de cambios en los déficit atencionales intermedios de estudiantes universitarios de Barranquilla sometidos al Método de Autocontrol de la Atención (Mindfulness). Revista Salud Uninorte, 23(2), 184-192.

Biederman, J., Mick, E., Fried, R., Wilner, N., Spencer, T. J., \& Faraone, S. V. (2012). ¿Son los estimulantes efectivos en el tratamiento de los déficits de funciones ejecutivas? Resultados de un estudio aleatorizado doble ciego sobre tratamiento con metilfenidato OROS en adultos con trastorno por déficit de atención con hiperactividad. Psiquiatría Biológica, 19(1), 1-8. https://doi.org/10.1016/j.psiq.2012.02.004

Cáceres, P. (2008). Análisis cualitativo de contenido: Una alternativa metodológica alcanzable. Psicoperspectivas. Individuo y Sociedad, 2(1), 53-82.

Cardo, E., \& Servera, M. (2008). Trastorno por déficit de atención/hiperactividad: estado de la cuestión y futuras líneas de investigación. Rev neurol, 46(6), 365-372.

Chung, H., Weyandt, L. \& Swentosky, A. (2014) The Physiology of Executive. En Goldstein, S., \& Naglieri, J. A. (Eds.). (2014). Handbook of Executive Functioning. New York, NY: Springer New York

Davidson, M. A. (2007). Literature Review: ADHD in Adults: A Review of the Literature. Journal of Attention Disorders, 11(6), 628-641. https://doi.org/10.1177/1087054707310878

Faraone, S. V. (2005). What Is the Prevalence of Adult ADHD? Results of a Population Screen of 966 Adults. Journal of Attention Disorders, 9(2), 384-391. https://doi.org/10.1177/1087054705281478 
Garello, M. V., \& Rinaudo, M. C. (2013). Autorregulación del aprendizaje, feedback y transferencia de conocimiento. Investigación de diseño con estudiantes universitarios. Revista Electrónica de Investigación Educativa, 15(2). Recuperado a partir de http://redie.uabc.mx/redie/article/view/451

Geertz, C. (1987). La interpretación de las culturas. Barcelona: Gedisa.

Gioia, G. A., Isquith, P.K., Guy, S. C., \& Kenworthy, L. (2000). Behavior Rating Inventory of Executive Function. Professional Manual. Psychological Assessment Resources, Inc.

Gioia, G. A., Isquith, P.K., Guy, S. C., Kenworthy, L. (2015). Behavior Rating Inventory of Executive Function. (2da. ed.). Professional Manual. Psychological Assessment Resources, Inc. EE.UU.: PAR.

Goldstein, S., \& Naglieri, J. A. (Eds.). (2014). Handbook of Executive Functioning. New York, NY: Springer New York. Recuperado a partir de http://link.springer.com/10.1007/978-1-4614-8106-5

LaCount, P. A., Hartung, C. M., Shelton, C. R., \& Stevens, A. E. (2015). Efficacy of an Organizational Skills Intervention for College Students With ADHD Symptomatology and Academic Difficulties. Journal of Attention Disorders, 1087054715594423.

Lavigne, R., \& Romero, J. F. (2010). EI TDAH:¿ Qué es?, ¿ Qué lo causa?, ¿ Cómo evaluarlo y tratarlo. Madrid: Pirámide.

Lezak, M. D. (1982). The problem of assessing executive functions. International journal of Psychology, 17(1-4), 281297.

Marx, I., Höpcke, C., Berger, C., Wandschneider, R., \& Herpertz, S. C. (2013). The Impact of Financial Reward Contingencies on Cognitive Function Profiles in Adult ADHD. PLoS ONE, 8(6), e67002. https://doi.org/10.1371/journal.pone.0067002

Miranda, A., Presentacion, M. J., Siegenthaler, R., \& Jara, P. (2013). Effects of a Psychosocial Intervention on the Executive Functioning in Children With ADHD. Journal of Learning Disabilities, 46(4), 363-376. https://doi.org/10.1177/0022219411427349

Miranda-Casas, A., Soriano-Ferrer, M., Presentación-Herrera, M., \& Gargallo-López, B. (2000). Intervención psicoeducativa en estudiantes con trastorno por déficit de atención con hiperactividad. Rev Neurol Clin, 1, 203-216

Montiel-Navas, C., Ortiz, S., Jaimes, A., \& González-Avila, Z. (2012). Prevalencia del trastorno por déficit de atenciónhiperactiviad en estudiantes universitarios venezolanos. Reporte preliminar. Investigación Clínica, 53, 353-364.

Murray, L. L., \& Ramage, A. E. (2000). Assessing the executive function abilities of adults with neurogenic communication disorders. En Seminars in speech and language (Vol. 21, pp. 0153-0168). Copyrightlcopyright 2000 by Thieme Medical Publishers, Inc., 333 Seventh Avenue, New York, NY 10001, USA. Tel.:+ 1 (212) 584-4663. Recuperado a partir de https://www.thieme-connect.com/products/ejournals/abstract/10.1055/s-2000-7562

Naglieri, J. A., \& Otero, T. M. (2014). The Assessment of Executive Function Using the Cognitive Assessment System: Second Edition. En Handbook of Executive Functioning Springer New York. New York, NY. Recuperado a partir de http://link.springer.com/10.1007/978-1-4614-8106-5

Newark, P. E., \& Stieglitz, R.-D. (2010). Therapy-relevant factors in adult ADHD from a cognitive behavioural perspective. ADHD Attention Deficit and Hyperactivity Disorders, 2(2), 59-72. https://doi.org/10.1007/s12402-0100023-1

Nigg, J. T., Stavro, G., Ettenhofer, M., Hambrick, D. Z., Miller, T., \& Henderson, J. M. (2005). Executive functions and adhd in adults: Evidence for selective effects on ADHD symptom domains. Journal of Abnormal Psychology, 114(4), 706-717. https://doi.org/10.1037/0021-843X.114.3.706

Olmedo Moreno, E. M. (2013). Enfoques de aprendizaje de los estudiantes y metodología docente: Evolución hacia el nuevo sistema de formación e interacción propuesta en el EEES. Revista de Investigación Educativa, 31(2). https://doi.org/10.6018/rie.31.2.133501

Pineda, David. (2000). La función ejecutiva y sus trastornos. Rev neurol, 30(8), 764-768.

Ramos Galarza, C. A., \& Pérez Salas, C. P. (2015). Relación entre el modelo híbrido de las funciones ejecutivas y el trastorno por déficit de atención con hiperactividad. Psicología desde el Caribe, 32(2), 299-314. 
Ramos-Quiroga, J. A., Bosch-Munsó, R., Castells-Cervelló, X., Nogueira-Morais, M., García-Giménez, E., \& CasasBrugué, M. (2006). Trastorno por déficit de atención con hiperactividad en adultos: caracterización clínica y terapéutica. Rev Neurol, 42(10), 600-606.

Ramos-Quiroga, J. A., Díaz-Digon, L., Comín, M., Bosch, R., Palomar, G., Chalita, J. P., Casas, M. (2012). Criteria and concurrent validity of adult ADHD section of the psychiatry research interview for substance and mental disorders. Journal of attention disorders, 19(12), 999-1006.

Ramos-Quiroga, J. A., Montoya, A., Kutzelnigg, A., Deberdt, W., \& Sobanski, E. (2013). Attention deficit hyperactivity disorder in the European adult population: prevalence, disease awareness, and treatment guidelines. Current Medical Research and Opinion, 29(9), 1093-1104. https://doi.org/10.1185/03007995.2013.812961

Rodríguez-Jiménez, R., Cubillo, A. I., Jiménez-Arriero, M. A., Ponce, G., Aragüés-Figuero, M., \& Palomo, T. (2006). Disfunciones ejecutivas en adultos con trastorno por déficit de atención e hiperactividad. Revista de neurología, 43(11), 678-684.

Roizblatt, A., Bustamante, F., \& Bacigalupo, F. (2003). Trastorno por déficit atencional con hiperactividad en adultos. Revista médica de Chile, 131(10), 1195-1201.

Rosário, P., Lourenço, A., Paiva, M. O., Núñez, J. C., González-Pienda, J., \& Valle, A. (2012). Autoeficacia y utilidad percibida como condiciones necesarias para un aprendizaje académico autorregulado. Anales de psicología, 28(1). Recuperado a partir de http://repositorium.sdum.uminho.pt/handle/1822/14907

Rostain, A. L., \& Ramsay, J. R. (2006). A Combined Treatment Approach for Adults With ADHD--Results of an Open Study of 43 Patients. Journal of Attention Disorders, 10(2), 150-159. https://doi.org/10.1177/1087054706288110

Servera-Barceló, M. (2005). Modelo de autorregulación de Barkley aplicado al trastorno por déficit de atención con hiperactividad: una revisión. Revista de neurología, 40(6), 358-368.

Shaw, M., Hodgkins, P., Caci, H., Young, S., Kahle, J., Woods, A. G., \& Arnold, L. E. (2012). A systematic review and analysis of long-term outcomes in attention deficit hyperactivity disorder: effects of treatment and non-treatment. BMC medicine, 10(1), 99.

Simons, H. (2011). El Estudio de Caso: Teoría y práctica . Ediciones Morata.

Silva Laya, M. (2011). El primer año universitario: Un tramo crítico para el éxito académico. Perfiles educativos, 33(SPE.), 102-114.

Soprano, A. M. (2003). Evaluación de las funciones ejecutivas en el niño. Revista de neurología, 37(1), 44-50.

Stake, R. E. (1998). Investigación con estudio de casos. Madrid: Morata. 